\title{
Detección de Leptospira spp. en animales y muestras ambientales de áreas peridomésticas en Nicaragua
}

\author{
Álvaro Chávez, ${ }^{1}$ Byron Flores Somarriba, ${ }^{1}$ Aida Soto, ${ }^{2}$ Jessica Sheleby-Elías, ${ }^{1}$ \\ Christiane Duttmann, ${ }^{1}$ Eduardo Jiménez, ${ }^{3}$ Eveling Pérez, ${ }^{1}$ Brenda Mora ${ }^{1}$ y \\ William Jirón ${ }^{1}$
}

Forma de citar Chávez A, Flores Somarriba B, Soto A, Sheleby-Elías J, Duttmann Ch, Jiménez E, et al. Detección de Leptospira spp. en animales y muestras ambientales de áreas peridomésticas en Nicaragua. Rev Panam Salud Publica. 2018;42:e26. https://doi.org/10.26633/RPSP.2018.26

RESUMEN Objetivo. El objetivo de este estudio fue conocer las características epidemiológicas de la leptospirosis en animales domésticos y en los casos de leptospirosis humana en áreas peridomésticas en Nicaragua entre 2014 y 2016.

Métodos. Las muestras se extrajeron en áreas donde se confirmaron casos en humanos utilizando un muestreo no probabilístico en 10 de los 17 departamentos del país. Se incluyeron 112 muestras de orina de animales domésticos, 129 muestras de agua y 69 de tierra para aislar leptospiras en medio Ellinghausen-McCullough-Johnson-Harris (EMJH). Además, se aplicó la prueba de microaglutinación (MAT) en 263 muestras de suero de animales y 88 aislados se analizaron mediante PCR.

Resultados. En 32,6\% (101/310) de las muestras se aislaron espiroquetas, 23,2\% (26/112) se aislaron en la orina de animales domésticos, 47,3\% (61/129), en las muestras de agua y $20,3 \%(14 / 69)$, en las de tierra. El análisis de aislamiento mostró diferencias significativas $(P<0,05)$ entre los departamentos para los diferentes tipos de muestras, y el aislamiento fue más frecuente en agua que en tierra (OR =3,49; IC95\%: 1,56-7,80). El 14,1\% (37/263) de los animales fueron reactores en la prueba de microaglutinación. El serogrupo más frecuente fue Icterohaemorrhagiae (40\%). En el análisis con la PCR para identificar leptospiras de las especies patógenas 10,2\% (9/88) de los aislamientos fueron positivos.

Conclusiones. Esta investigación demuestra que los animales domésticos y el ambiente desempeñan un papel importante en la aparición de brotes de la leptospirosis y confirma el comportamiento endémico de la enfermedad en Nicaragua.

Palabras clave Leptospirosis; factores epidemiológicos; zoonosis; Nicaragua.

En Nicaragua, la leptospirosis se conoció como fiebre de Achuapa en 1995 (1). En octubre de ese año, en el municipio de Achuapa se observó un aumento del número de pacientes con fiebre, dolor de cabeza, escalofríos y dolor musculoesquelético; tres fallecieron. En las semanas siguientes se declararon 400 casos en Achuapa y El Sauce, de los cuales 150 fueron hospitalizados con un cuadro más grave (dolor abdominal, hipotensión y distrés respiratorio). Al menos 13 de ellos murieron por distrés respiratorio y hemorragia pulmonar. No se observaron ictericia ni
Nicaragua-León (UNAN-León), León, Nicaragua. La correspondencia se debe dirigir a Byron Flores. byronfloressomarriba@gmail.com

\footnotetext{
Organización Panamericana de la Salud, Managua, Nicaragua.

Ministerio de Salud, Managua, Nicaragua.
} 
manifestaciones renales (2). Se afirmó que las principales características del ecosistema que favorecieron la transmisión de la bacteria fueron las lluvias abundantes con desbordamientos de los ríos y las aguas residuales contaminadas con orina de animales infectados $(3,4)$.

Algunos estudios revelan una alta incidencia de leptospirosis humana en Nicaragua $(4,5)$. Las incidencias acumuladas por municipios oscilan entre $0 \mathrm{y}$ 11,36 por 10000 habitantes. Los departamentos con mayor incidencia acumulada son León y Chinandega con 36,03 y 18,84 por 10000 habitantes, respectivamente (4). Actualmente se conoce mejor el comportamiento de la enfermedad debido a que en los últimos años se ha mejorado el sistema de vigilancia epidemiológica. Además, se ha desplegado un plan de trabajo interinstitucional de abordaje integral para la prevención y el control de la leptospirosis en los municipios priorizados por los Sistemas Locales de Atención Integral en Salud (SILAIS)", mediante el cual se realiza el control de focos. En dicho plan participan el Ministerio de Salud (MINSA), el Instituto de Protección y Sanidad Animal (IPSA), la Escuela de Ciencias Agrarias y Veterinarias de la Universidad Nacional Autónoma de Nicaragua, León (UNAN-León), y la Representación de la Organización Panamericana de Salud (OPS) en Nicaragua (6). El objetivo de este estudio fue conocer las características epidemiológicas de la leptospirosis en animales domésticos y en los casos de leptospirosis humana en áreas peridomésticas en Nicaragua entre 2014 y 2016.

\section{MATERIALES Y MÉTODOS}

El área del estudio fue Nicaragua, un país centroamericano con clima tropical (se localiza $10^{\circ} 45^{\prime}$ y $15^{\circ} 15^{\prime}$ de latitud norte y $83^{\circ} 00^{\prime}$ y $88^{\circ} 00^{\prime}$ longitud oeste) (7). El estudio se realizó en 10 de los 17 departamentos del país. En las zonas Central y Norte se incluyeron los departamentos de Boaco, Jinotega, Madriz, Matagalpa y Nueva Segovia. Esta zona se caracteriza por su topografía montañosa, con precipitaciones anuales entre 800 y $2500 \mathrm{~mm}$ y temperaturas cercanas a los $26^{\circ} \mathrm{C}$. En la zona del Pacífico se obtuvieron muestras en los departamentos de Chinandega, León, Rivas, Managua y Masaya. Esta es la región volcánica y lacustre del país, con precipitaciones anuales que oscilan entre 1000 y 2000 mm y una temperatura media cercana a los $34{ }^{\circ} \mathrm{C}(8)$.

Las muestras se extrajeron mediante un muestreo no probabilístico de animales de ambos sexos, en áreas urbanas, $30 \mathrm{~m}$ alrededor de la vivienda de pacientes con leptospirosis humana y $100 \mathrm{~m}$ en áreas rurales. Los casos en humanos fueron confirmados por el MINSA con la prueba de aglutinación microscópica (MAT) en muestras apareadas. En viviendas con varios animales de la misma especie, se muestreó al menos un animal por especie mediante muestreo aleatorio simple. Las muestras de orina se recolectaron por estimulación de la micción en bovinos y equinos, mientras que en caninos, porcinos y felinos se obtuvieron por punción de la vejiga. Se recolectaron 263 muestras de sangre: 159 en caninos, 36 en bovinos, 60 en porcinos, 7 en equinos y 1 en un felino. Para el aislamiento a partir de la orina, se recolectaron 112 muestras, 75 en caninos, 22 en porcinos y 15 en bovinos.

Se extrajeron, asimismo, 129 muestras de agua de diferentes fuentes, como la almacenada en pozos, ríos, charcas y en la red de distribución pública, todas ellas cercanas o dentro de las viviendas de los pacientes con leptospirosis humana. En los ríos se obtuvieron muestras de áreas protegidas de los rayos solares y con menor flujo. Se recolectó 1L en frascos estériles y las muestras se transportaron a $4{ }^{\circ} \mathrm{C}$ al laboratorio de leptospirosis en el Centro Veterinario de Diagnóstico e Investigación (CEVEDI).

También se obtuvieron 69 muestras de tierra, recolectando $10 \mathrm{~g}$ por muestra en un frasco estéril en áreas húmedas cercanas al lugar de permanencia de los animales, en la cocina y en lugares de almacenamiento de los alimentos.

Para realizar los aislamientos en las muestras seleccionadas, se utilizó la guía descrita por la Organización Mundial de la Salud (OMS) (9). Para el aislamiento a partir de las muestras de tierra, se pesaron $5 \mathrm{~g}$ de cada muestra, que se suspendieron en $10 \mathrm{ml}$ de agua destilada estéril manteniendo los tubos en posición vertical durante 1 hora. Posteriormente, se tomó $1 \mathrm{ml}$ del sobrenadante de la muestra y se mezcló con $5 \mathrm{ml}$ del medio Ellinghausen-McCullough-Johnson-Harris (EMJH) (Difco®, Estados Unidos de América) combinado con $40 \mu \mathrm{g} / \mathrm{mL}$ de sulfametoxazol, $20 \mu \mathrm{g} / \mathrm{ml}$ de trimetoprim, $5 \mu \mathrm{g} / \mathrm{ml}$ de anfotericina B, $400 \mu \mathrm{g}$ / $\mathrm{ml}$ de fosfomicina y $100 \mu \mathrm{g} / \mathrm{ml}$ de 5-fluorouracilo (10). Las muestras de agua y orina de los animales domésticos se filtraron con membranas de 0,22 $\mu \mathrm{m}$ y luego se inocularon 2 o 3 gotas (aproximadamente $50 \mu \mathrm{l}$ ) en $5 \mathrm{ml}$ de EMJH + 5-fluorouracilo. Todas las muestras se incubaron a $27-30{ }^{\circ} \mathrm{C}$ durante 16 semanas. Cada 8 días se observaron al microscopio de campo oscuro y se realizaron subcultivos de las muestras con crecimiento de espiroquetas. Una muestra se consideró positiva cuando se obtuvo crecimiento en al menos uno de ellos.

Para efectuar el análisis mediante la MAT, se siguieron los protocolos descritos por la Organización Mundial de la Salud (9). Se utilizaron 22 muestras en 2014, 132 en 2015 y 109 en 2016. La primera fase consistió en realizar el análisis cualitativo con una dilución de suero 1:200 para identificar los posibles serogrupos. En la segunda fase, se realizó un análisis cuantitativo con diluciones seriadas de los sueros desde 1:200 hasta 1:25 600. En ambas pruebas se utilizaron como antígenos 30 cepas de referencia, distribuidas en 6 especies patógenas y 2 saprófitas, que eran representativas de 24 serogrupos. (Información disponible previa solicitud a los autores.) El Centro Nacional de Diagnóstico y Referencia (CNDR) proporcionó el panel de cepas de referencia al laboratorio de microbiología del CEVEDI de la Escuela de Ciencias Agrarias y Veterinarias de la UNAN en León.

Las espiroquetas aisladas postincubación después de 7 días se centrifugaron a 17500 x g durante $10 \mathrm{~min}$ (11) y se tomaron $200 \mu \mathrm{l}$ del precipitado para realizar la extracción del ADN siguiendo las indicaciones del kit comercial UltranClean $\AA$ Blood Spin de MO BIO, Estados Unidos de América).

Para hacer la ampliación, se siguieron dos protocolos. El primero consistió en aplicar el ensayo descrito por Levett, et al. (11) con los cebadores LipL32-270F (5'-CGCTGAAATGGGAGTTCGTATGATT-3') y LipL32-692R (5'-CCAACAGATGCAACGAAAGATCCTTT-3’), que flanquean una ampliación de 423 pb correspondiente al gen LipL32, único en las especies de leptospiras patógenas. El segundo ensayo se aplicó siguiendo el protocolo descrito por Merien, et al. (12) con los cebadores LFB1-F (5'-TAGGAAATTGCGCAGCTACA-3') y LFB1-R (5'GGCCCAAGTTCCTTCTAAAAG -3'), que amplifican un segmento de $331 \mathrm{pb}$ en las especies patógenas. 
El análisis descriptivo de los datos consistió en la estimación de las frecuencias relativas con sus respectivos intervalos de confianza de 95\% (IC95\%). Para comparar variables categóricas con grupos independientes, se utilizó la prueba de Chi cuadrado. Esta prueba se realizó cuando se encontró menos de $20 \%$ de las celdas en las tablas de contingencia, con frecuencias esperadas menores de 5 (fundamentalmente en los resultados de la MAT). En los casos en que no se cumplió dicho criterio, se aplicó la prueba exacta de Fisher. Para averiguar la existencia de asociaciones entre variables independientes (mes, tipo de muestra, departamento y año) con la variable dependiente aislamientos de espiroqueta (positivos o negativos) y año, especie y departamento con la variable dependiente prueba de microaglutinación (positiva o negativa), así como para controlar variables confusoras, se realizaron estratificaciones por las variables independientes y se construyó un modelo de regresión logística binaria en cada caso. Su bondad de ajuste se analizó con la prueba de Hosmer y Lemeshow.

Los procedimientos los realizaron veterinarios de la Escuela de Ciencias Agrarias y Veterinarias de la UNAN-León. En cada caso se contó con el consentimiento informado de los propietarios de los animales domésticos y las viviendas y se garantizó la confidencialidad de los datos de los pacientes antes de realizar las actividades. El muestreo en animales domésticos se hizo con la aprobación y participación del IPSA y las visitas a las viviendas de los pacientes y sus alrededores, con la aprobación y participación del MINSA como parte de la vigilancia activa de la leptospirosis en Nicaragua.
Las cuatro instituciones participantes (UNAN-León, IPSA, MINSA, OPS/ OMS) forman parte de la Comisión Nacional de Zoonosis, de la cual surgió la propuesta de realizar este estudio.

\section{RESULTADOS}

Se encontraron espiroquetas en $32,6 \%$ (IC95\%: 27,2-37,9) de todas las muestras analizadas mediante aislamiento. El 23,2\% (IC95\%: 14,9-31,5) de las muestras de orina de animales domésticos, 47,3\% (IC95\%: 38,3-56,3) de las muestras de agua y 20,3\% (IC95\%:10,1-30,5) de tierra fueron positivas en el aislamiento. La estratificación de los resultados del aislamiento de las diferentes muestras por departamentos reveló que en Rivas 50\% (7/14) de los animales fueron positivos, mientras que solo en $4,3 \%(1 / 23)$ de los animales de Matagalpa se observó crecimiento $(\mathrm{P}<0,05)$. En las muestras de agua de Nueva Segovia y Rivas los porcentajes de aislamientos fueron altos, $85 \%(17 / 20)$ y $72,2 \%(13 / 18)$, respectivamente, mientras en Madriz no se obtuvieron aislamientos $(0 / 2) \quad(P<0,01)$. En las muestras de tierra también se observaron diferencias estadísticamente significativas en los porcentajes de aislamientos entre los departamentos $(\mathrm{P}<0,01)$. En Nueva Segovia y Rivas se obtuvo el porcentaje más alto de aislamientos (cuadro 1).

Los porcentajes de aislamientos positivos más elevados se observaron en 2016, $51,1 \%(23 / 45)$ en animales domésticos, $74,1 \%(43 / 58)$ en muestras de agua $y$ $58,8 \%(10 / 17)$ en muestras de tierra y las diferencias entre ellos fueron estadísticamente significativas $(\mathrm{P}<0,01)$ (cuadro 2 ). En octubre se detectó la frecuencia más alta de aislamientos positivos en animales, agua y tierra: 55,2\% (16/29), 77,1\% $(37 / 48)$ y $57,1 \%(8 / 14)$, respectivamente, y las diferencias entre ellos también fueron estadísticamente significativas $(\mathrm{P}<0,01)$ (cuadro 3).

Los porcentajes de positividad al aislamiento en muestras de agua fueron los siguientes: aguas estancadas 100\% (3/3), agua de río $81,3 \%(13 / 16)$, agua de pozo $57,1 \%(16 / 28)$ y agua almacenada $40,0 \%$ $(22 / 55)$ (cuadro 4). En el modelo de regresión logística las muestras de agua tuvieron mayor probabilidad de ser positivas respecto a las de tierra. En 2015, la probabilidad de encontrar muestras positivas en el aislamiento fue menor que en 2016, mientras que en 2014 esta probabilidad fue similar a la de 2016 (cuadro 5).

El 14,1\% (37/263) de los animales fueron reactores en la prueba de microaglutinación. Un animal mostró reacción a dos serogrupos y uno, a tres serogrupos. El serogrupo más frecuente fue Icterohaemorrhagiae con $43,2 \%(16 / 37)$, seguido por Canicola 16,2\% (6/37), Hebdomadis y Louisiana 13,5\% (5/37), Pyrogenes 10,8\% (4/37), y Pomona $8,1 \%$ (3/37). El reactor menos frecuente $(2,7 \%)$ fue Sejroe $(1 / 37)$. El serogrupo Icterohaemorrhagiae se encontró en todas las especies de animales de los que se obtuvieron muestras a excepción de los porcinos y no se encontró asociación entre el serogrupo y las especies $(P \geq 0,05)$. El serogrupo Icterohaemorrhagiae fue el más frecuente en los departamentos de Chinandega, Boaco, Masaya, Managua y Nueva Segovia, mientras que en Rivas el más frecuente fue el serogrupo Canicola $(\mathrm{P}<0,05)$.

En la regresión logística para los resultados de la prueba de microaglutinación

CUADRO 1. Estratificación de los aislamientos positivos a espiroquetas en las diferentes muestras por departamentos de Nicaragua, 2014-2016

\begin{tabular}{|c|c|c|c|c|c|c|c|}
\hline \multirow{2}{*}{ Departamento } & Animales & \multirow{2}{*}{$P^{2}$} & Aguas & \multirow{2}{*}{$P^{2}$} & Tierra & \multirow{2}{*}{$P^{2}$} & \multirow{2}{*}{ Total de muestras } \\
\hline & \% (número/total) & & $\%$ (número/total) & & $\%$ (número/total) & & \\
\hline Chinandega & $12(3 / 25)$ & & $60(6 / 10)$ & & $42,9(3 / 7)$ & & 42 \\
\hline Jinotega & $39,1(9 / 23)$ & & $50(8 / 16)$ & & $50(1 / 2)$ & & 41 \\
\hline León & $22,7(5 / 22)$ & & $27,3(6 / 22)$ & & $37,5(3 / 8)$ & & 52 \\
\hline Madriz & $\ldots$ & $<0,05$ & $0(0 / 2)$ & $<0,01$ & NA & $<0,01$ & 2 \\
\hline Matagalpa & $4,3(1 / 23)$ & & $26,8(11 / 41)$ & & $0(0 / 40)$ & & 104 \\
\hline Nueva Segovia & $20(1 / 5)$ & & $85(17 / 20)$ & & $60(3 / 5)$ & & 30 \\
\hline Rivas & $50(7 / 14)$ & & $72,2(13 / 18)$ & & $57,1(4 / 7)$ & & 39 \\
\hline Total de muestras & 112 & & 129 & & 69 & & 310 \\
\hline
\end{tabular}

Fuente: elaboración propia a partir de los datos del estudio.

${ }^{1}$ En los departamentos de Boaco, Managua y Masaya no se tomaron muestras para el aislamiento.

${ }^{2}$ Valor $P$ de la prueba exacta de Fisher. 
CUADRO 2. Aislamientos positivos a espiroquetas en las diferentes muestras por años de muestreo, Nicaragua, 2014-2016

\begin{tabular}{|c|c|c|c|c|c|c|c|}
\hline \multirow{2}{*}{ Año } & Animales & \multirow{2}{*}{$P^{1}$} & Agua & \multirow{2}{*}{$P^{1}$} & Tierra & \multirow{2}{*}{$P^{1}$} & \multirow{2}{*}{$\begin{array}{l}\text { Total de } \\
\text { muestras }\end{array}$} \\
\hline & $\%$ (número/total) & & $\overline{\% \text { (número/total) }}$ & & $\overline{\% \text { (número/total) }}$ & & \\
\hline 2014 & $5,9(1 / 17)$ & & $0(0 / 8)$ & & NA & & 25 \\
\hline 2015 & $4(2 / 50)$ & $<0,01$ & $28,6(18 / 63)$ & $<0,01$ & $7,7(4 / 52)$ & $<0,01$ & 165 \\
\hline 2016 & $51,1(23 / 45)$ & & $74,1(43 / 58)$ & & $58,8(10 / 17)$ & & 120 \\
\hline $\begin{array}{l}\text { Total de } \\
\text { muestras }\end{array}$ & 112 & & 129 & & 69 & & 310 \\
\hline
\end{tabular}

Fuente: elaboración propia a partir de los datos del estudio.

Valor $P$ de la prueba exacta de Fisher.

CUADRO 3. Porcentajes de aislamientos positivos a espiroquetas en las diferentes muestras por mes, Nicaragua, 2014-2016

\begin{tabular}{|c|c|c|c|c|c|}
\hline \multirow{2}{*}{ Mes } & Animales & Agua & Tierra & \multirow{2}{*}{$P^{1}$} & \multirow{2}{*}{ Total de muestras } \\
\hline & $\%$ (número/total) & $\%$ (número/total) & \% (número/total) & & \\
\hline Febrero & $0(0 / 2)$ & NA & NA & NA & 2 \\
\hline Abril & $0(0 / 2)$ & NA & NA & NA & 2 \\
\hline Junio & $5,9(1 / 17)$ & $0(0 / 8)$ & NA & $\geq 0,05$ & 25 \\
\hline Julio & $13,0(3 / 23)$ & NA & NA & NA & 23 \\
\hline Septiembre & NA & $0(0 / 2)$ & NA & NA & 2 \\
\hline Octubre & $55,2(16 / 29)$ & $77,1(37 / 48)$ & $57,1(8 / 14)$ & $\geq 0,05$ & 91 \\
\hline Noviembre & $8,3(3 / 36)$ & $36,5(23 / 63)$ & $9,4(5 / 53)$ & $<0,01$ & 152 \\
\hline Diciembre & $0(0 / 3)$ & $12,5(1 / 8)$ & $50,0(1 / 2)$ & $\geq 0,05$ & 13 \\
\hline$P^{1}$ & $<0,01$ & $<0,01$ & $<0,01$ & & \\
\hline Total de muestras & 112 & 129 & 69 & & 310 \\
\hline
\end{tabular}

Fuente: elaboración propia a partir de los datos del estudio.

${ }^{1}$ Valor $P$ de la prueba exacta de Fisher.

NA: no aplicable.

CUADRO 4. Aislamientos de espiroquetas según las diferentes fuentes de agua estratificados por departamento, Nicaragua, 2014-2016

\begin{tabular}{llcc}
\hline \multicolumn{1}{c}{ Departamento } & \multicolumn{1}{c}{ Fuente de agua ${ }^{1}$} & Positivos/total de muestras & $P$ \\
\hline Chinandega & Agua almacenada & $1 / 2$ & $\geq 0,05^{2}$ \\
& Agua de pozo & $4 / 5$ & \\
Jinotega & Río & $1 / 2$ & $\geq 0,05^{2}$ \\
& Agua almacenada & $5 / 11$ & \\
León & Agua de pozo & $1 / 3$ & $\geq 0,05^{2}$ \\
& Río & $2 / 2$ & \\
Madriz & Agua almacenada & $1 / 10$ & \\
Matagalpa & Agua de pozo & $2 / 7$ & \\
Nueva Segovia & Río & $2 / 4$ & $\geq 0,05^{2}$ \\
& Agua almacenada & $0 / 2$ & \\
& Agua almacenada & $5 / 16$ & \\
Rivas & Agua almacenada & $3 / 5$ & \\
& Agua de pozo & $7 / 8$ & \\
& Río & $7 / 7$ & \\
& Agua almacenada & $7 / 9$ & \\
Total & Agua de pozo & $2 / 5$ & \\
& Agua estancada & $3 / 3$ & \\
& Río & $1 / 1$ & \\
& Agua almacenada & $22 / 55$ & \\
& Agua de pozo & $16 / 28$ & \\
\hline
\end{tabular}

Fuente: elaboración propia a partir de los datos del estudio.

${ }^{1}$ En 27 muestras no fue posible obtener el dato del tipo de fuente de agua.

${ }^{2}$ Valor $P$ de la prueba exacta de Fisher.

${ }^{3}$ Valor $P$ de la prueba de Chi cuadrado. se encontró que los años y los departamentos se asociaron con el resultado positivo de la prueba, y la probabilidad de encontrar reactores en 2015 respecto a 2016 fue mayor, mientras que la probabilidad de reactores fue significativamente menor $(P<0,05)$ en los departamentos de Chinandega y Nueva Segovia respecto al departamento de Rivas (cuadro 6).

En el análisis con la PCR para identificar leptospiras de las especies patógenas, $10,2 \%(9 / 88)$ de los aislamientos fueron positivos a la prueba y no se encontró ninguna asociación del resultado con los departamentos $(P \geq 0,05)$ ni con el tipo de muestra $(P \geq 0,05)$.

\section{DISCUSIÓN}

Como en Nicaragua las leptospiras están ampliamente distribuidas en animales $\mathrm{y}$, por consiguiente, en la tierra y en las aguas, cabe esperar altas incidencias de esta enfermedad en humanos (4). La orina de animales infectados es una fuente de transmisión directa o indirecta para los humanos, lo que se suma a que las condiciones climáticas del país facilitan la supervivencia de la espiroqueta en el ambiente $(4,7,9)$. En este estudio se ha encontrado un elevado porcentaje de aislamientos de leptospiras en la orina, el agua y la tierra en zonas donde la leptospirosis es endémica, lo que podría implicar un aumento de la aparición de nuevos casos o brotes.

En términos generales, los ríos de Nicaragua y de otros países de la zona se utilizan con fines recreativos, limpieza y para consumo animal y humano $(5,16)$, lo que los convierte en un factor principal de infección. La elevada frecuencia de ríos contaminados se puede relacionar con el acceso de los animales a ellos, donde vierten grandes cantidades de orina que puede estar infestada con leptospiras. Otros estudios reflejan hallazgos similares de aislamientos de leptospiras en muestras de agua $(14,15)$.

Los departamentos incluidos en este estudio tienen un alto porcentaje de suelos del tipo cambisol y ambisol y ello facilita la retención de humedad en épocas lluviosas. Además, su pH alcalino puede contribuir a explicar la alta frecuencia de aislamientos (4). El uso del medio EMJH suplementado con sulfametoxazol, trimetoprim, anfotericina B, fosfomicina y 5-fluorouracilo pudo haber aumentado el porcentaje de espiroquetas aisladas (17). La utilización de estos antibióticos puede reducir la contaminación del 
CUADRO 5. Regresión logística para el aislamiento de espiroqueta, Nicaragua, 2014-2016

\begin{tabular}{|c|c|c|c|c|}
\hline \multirow{2}{*}{ Variables } & \multirow{2}{*}{$\begin{array}{l}\text { Categorías de las } \\
\text { variables }\end{array}$} & \multirow{2}{*}{ Odds ratio } & \multicolumn{2}{|c|}{ IC95\% } \\
\hline & & & Inferior & Superior \\
\hline \multirow[t]{8}{*}{ Mes } & Diciembre $^{1}$ & & & \\
\hline & Febrero & 0 & & \\
\hline & Abril & 0 & & \\
\hline & Junio & 0 & & \\
\hline & Julio & 0,01 & 0 & 1,95 \\
\hline & Septiembre & 0 & & \\
\hline & Octubre & 0 & & \\
\hline & Noviembre & 0,82 & 0,04 & 15,38 \\
\hline \multirow[t]{3}{*}{ Tipo de muestra } & Tierra $^{1}$ & & & \\
\hline & Animales domésticos & 1,5 & 0,53 & 4,28 \\
\hline & Agua & 3,49 & 1,56 & 7,80 \\
\hline \multirow{7}{*}{$\begin{array}{l}\text { Departamento } \\
\text { (región) }\end{array}$} & Rivas $^{1}$ & & & \\
\hline & Chinandega & 0 & & \\
\hline & Jinotega & 1,44 & 0,44 & 4,76 \\
\hline & León & 0 & & \\
\hline & Madriz & 0 & & \\
\hline & Matagalpa & 0 & & \\
\hline & Nueva Segovia & 1,08 & 0,37 & 3,18 \\
\hline \multirow[t]{3}{*}{ Año } & $2016^{1}$ & & & \\
\hline & 2015 & 0,03 & 0 & 0,31 \\
\hline & 2014 & 0 & & \\
\hline
\end{tabular}

Fuente: elaboración propia a partir de los datos del estudio.

${ }^{1}$ Categoría de referencia.

IC95\%: intervalo de confianza de $95 \%$.

Valor $P$ de la prueba de bondad de ajuste de Hosmer y Lemeshow $=0,397$.

CUADRO 6. Regresión logística para los resultados de la prueba de microaglutinación en animales domésticos, Nicaragua, 2014-2016

\begin{tabular}{|c|c|c|c|c|}
\hline \multirow{2}{*}{ Variable } & \multirow{2}{*}{$\begin{array}{l}\text { Categorías } \\
\text { de las variables }\end{array}$} & \multirow{2}{*}{ Odds ratio } & \multicolumn{2}{|c|}{ IC95\% } \\
\hline & & & Inferior & Superior \\
\hline \multirow[t]{3}{*}{ Año } & $2016^{1}$ & & & \\
\hline & 2015 & 5,55 & 1,28 & 24,1 \\
\hline & 2014 & 0 & & \\
\hline \multirow[t]{4}{*}{ Especie } & Porcinos ${ }^{1}$ & & & \\
\hline & Bovinos & 1,18 & 0,30 & 4,66 \\
\hline & Caninos & 1,62 & 0,58 & 4,56 \\
\hline & Equinos & 2,12 & 0,29 & 15,5 \\
\hline \multirow[t]{10}{*}{ Departamento } & Rivas $^{1}$ & & & \\
\hline & Boaco & 0,24 & 0,04 & 1,52 \\
\hline & Chinandega & 0,13 & 0,02 & 0,87 \\
\hline & Jinotega & 0,19 & 0,02 & 1,61 \\
\hline & León & 0 & & \\
\hline & Madriz & 0,16 & 0,01 & 2,91 \\
\hline & Managua & 0,16 & 0,02 & 1,19 \\
\hline & Masaya & 0,20 & 0,03 & 1,33 \\
\hline & Matagalpa & 0 & & \\
\hline & Nueva Segovia & 0,21 & 0,05 & 0,95 \\
\hline
\end{tabular}

Fuente: elaboración propia a partir de los datos del estudio.

${ }^{1}$ Categoría de referencia.

IC95\%: intervalo de confianza de 95\%.

Valor $P$ de la prueba de bondad de ajuste de Hosmer y Lemeshow $=0,989$.

medio y el sobrecrecimiento de otras bacterias diferentes de Leptospira spp.

En octubre, la época más lluviosa en el área estudiada, se encontraron los porcentajes de aislamientos positivos más altos. La humedad desempeña un papel fundamental en la transmisión de la bacteria a humanos y a animales, tanto por la vehiculización mecánica del agente desde especies reservorios, como por la maceración de la piel en las especies susceptibles, con la consiguiente entrada de la espiroqueta en el organismo (18-20). Estos resultados son congruentes con los obtenidos en estudios anteriores realizados en Nicaragua en los cuales se demostró una asociación entre la aparición de casos de leptospirosis y los meses con más precipitaciones $(5,21)$.

En este trabajo se pone de manifiesto una frecuencia de aislamientos significativamente mayor en muestras de ríos que en las de aguas estancadas. Sin embargo, en todas las fuentes de agua se encontró una elevada positividad a pesar de que otros estudios indican que el aislamiento de leptospiras a partir de muestras de aguas es difícil por la presencia otros agentes que pueden disminuir la sensibilidad de la técnica. Así se sugiere en un estudio que atribuyó la ausencia de aislamientos positivos en muestras de aguas estancadas a la presencia de otras bacterias menos exigentes para su crecimiento (22). Cabe mencionar que no se observaron diferencias significativas en la frecuencia del aislamiento entre las diferentes fuentes de agua cuando se estratificaron por departamentos, lo que puede estar influido por el bajo número de muestras analizadas en cada estrato (departamento).

En otros estudios se ha descrito la asociación de serogrupos con una especie animal en particular $(21,23)$, aunque esto no se ha observado en el presente trabajo. Este hecho podría estar enmascarado por la presencia de animales reactores a más de un serogrupo, como se ha descrito en otro estudio, en el cual se afirma que la posibilidad de coinfección con múltiples serovares es un factor que altera los resultados de la MAT en áreas de alta endemicidad (24). El serogrupo más frecuente, que se encontró en la mayoría de las especies de animales, fue Icterohaemorrhagiae. En Nicaragua se habían descrito resultados similares entre 2007 y 2013, lo que constituye una información que podría ser útil para diseñar e implantar programas de vacunación (21).

Los resultados de la regresión logística revelaron que una serología positiva se asocia con el año y los departamentos. En Rivas se estimó una probabilidad de obtener un resultado positivo más alta respecto a los departamentos de Chinandega y Nueva Segovia, lo que a su vez coincide con que Rivas fue uno de los departamentos con mayor incidencia acumulada 
de leptospirosis en humanos en 2016 $(4,29 / 10000$ habitantes, datos no publicados). Históricamente, los departamentos de León y Chinandega han presentado una alta incidencia de casos en humanos, si bien en los últimos años la leptospirosis ha aumentado en otros departamentos. Estos hechos traducen cambios en el comportamiento epidemiológico de la enfermedad.

El aumento anual observado en la positividad también se asocia con el ascenso del número de casos en humanos. Este hallazgo resalta la necesidad de seguir sumando esfuerzos en el control de la enfermedad, ya que como se plantea en otro estudio (21), en 2013 se presentaron pocos casos en humanos, aunque en él se observó un aumento de la frecuencia de animales positivos a la prueba de microaglutinación acompañado de un ascenso del número de casos en humanos.

En 2016, se obtuvo un mayor número aislamientos que puede estar asociado, entre otros factores, con el aumento de precipitaciones pluviales comprobado respecto a 2014 y a 2015 (25). Por otro lado, las mejoras en las capacidades diagnósticas de los laboratorios $(26,27)$, así como una mayor experiencia en el abordaje integral de los casos en humanos, pueden haber contribuido a una mejor captación de casos.

Los resultados de la PCR reflejan la presencia de leptospiras de las especies patógenas en el ambiente, principalmente en ríos, lo que podría estar relacionado con la aparición de casos en humanos que fueron registrados por el Ministerio de Salud (4 593 casos en el período estudiado, datos no publicados). No obstante, el número de estos casos es bajo si

1. Zaki SR, Shieh WJ. Leptospirosis associated with outbreak of acute febrile illness and pulmonary haemorrhage, Nicaragua, 1995. The Epidemic Working Group at Ministry of Health in Nicaragua. Lancet. 1996;347(9000):535-6.

2. Trevejo RT, Rigau-Pérez JG, Ashford DA, McClure EM, Jarquín-González C, Amador JJ, et al. Epidemic leptospirosis associated with pulmonary hemorrhageNicaragua, 1995. J Infect Dis. 1998; 178(5):1457-63.

3. From the Centers for Disease Control and Prevention. Outbreak of acute febrile illness and pulmonary hemorrhageNicaragua, 1995. JAMA. 1995;274(21):1668.

4. Schneider MC, Nájera P, Aldighieri S, Bacallao J, Soto A, Marquiño W, et al. Leptospirosis outbreaks in Nicaragua: se tiene en cuenta que estos ríos son utilizados de forma frecuente por los habitantes. Todo ello indica que en estas áreas se pueden producir infecciones, en su mayoría asintomáticas, tal como se refleja en un estudio realizado en el municipio de El Sauce, una zona hiperendémica donde se encontró una alta frecuencia de personas asintomáticas con títulos elevados de anticuerpos frente a Leptospira spp. (16). En este estudio, la PCR se aplicó a muestras con crecimiento de espiroquetas. En esta prueba un resultado negativo no debe considerarse como saprófita, ya que se ha demostrado que el ADN extraído puede contener inhibidores de la reacción que produzcan resultados negativos falsos (28).

Como limitación de este estudio cabe destacar que no se pudo realizar un muestreo probabilístico, ya que solo se extrajeron en áreas peridomésticas de los casos de leptospirosis humana. Por este motivo, los resultados no se pueden extrapolar al resto de la población.

En conclusión, esta investigación permite confirmar que la leptospirosis es endémica en Nicaragua. Los animales domésticos, las aguas ambientales y la tierra actúan como factores de riesgo en los brotes de la enfermedad. Estos factores deben tenerse en cuenta cuando se desarrollen planes estratégicos de prevención y control de la leptospirosis en humanos.

Agradecimientos. Los autores expresan su agradecimiento a la médico veterinaria Milagro Ramírez por su valiosa colaboración en el laboratorio, a los epidemiólogos del Sistema Local de Atención Integral en Salud (SILAIS), Dr. Gilberto Moreno (SILAIS-León), Dr. Octavio Chávez

\section{REFERENCIAS}

identifying critical areas and exploring drivers for evidence-based planning. Int J Environ Res Public Health. 2012; 9(11):3883-910.

5. Bacallao J, Schneider MC, Nájera $P$, Aldighieri S, Soto A, Marquiño W, et al. Socioeconomic factors and vulnerability to outbreaks of leptospirosis in Nicaragua. Int J Environ Res Public Health. 2014; 11(8):8301-18.

6. Soto A. Análisis preliminar del Plan Interinstitucional de abordaje integral a la Leptospirosis; 2012. Managua: Organización Panamericana de la Salud; 2012. Disponible en: http://www.paho. org / hq / index.php?option=com_docman\&task=doc_details\&gid $=19158 \&$ It emid=270\&lang=es Acceso el 6 de diciembre de 2017.
(SILAIS-Chinandega), Dr. Víctor Cruz (SILAIS-Rivas), Lic. Reina Jarquín (SILAIS-Jinotega), Lic. Byron García (SILAISMatagalpa), Lic. Rolando Guerrero (SILAIS-Boaco), Dra. Ligia Aragón (SILAIS-Managua), Dr. Leonel Jiménez (SILAIS-Masaya), Dr. Aldo Ponce (SILAISNueva Segovia), Dra. Mayra Reyes (SILAIS-Madriz), Dr. Alberto Montoya (Centro Nacional de Diagnóstico y Referencia) por facilitar las cepas de referencia y a Sergio Bermúdez, MSc (Instituto Conmemorativo Gorgas de Estudios de la Salud), por su colaboración en la revisión del documento. También agradecen la colaboración de los inspectores del Instituto de Protección y Sanidad Agropecuaria (IPSA), Dr. José María Pereira (PSA-León), Dr. César Brenes (IPSA-Rivas), Dr. Lener Palacios (IPSA-Jinotega), y Félix Gutiérrez (IPSA-Nueva Segovia). Por último, agradecen el apoyo prestado a este estudio por la Representación de la OPS/OMS en Nicaragua.

Financiación. Este trabajo fue financiado en parte por la OPS/OMS con la ayuda LOA-SCON2016-03767 y por la UNAN-León. Los patrocinadores no participaron en el diseño del estudio, ni en la recolección ni en el análisis de los datos. La decisión de publicar este trabajo fue iniciativa exclusiva de los autores.

Conflictos de interés. Los autores declaran no tener conflictos de interés.

Declaración. Las opiniones expresadas en este manuscrito son responsabilidad del autor y no reflejan necesariamente los criterios ni la política de la RPSP / PAJPH y/o de la OPS.
7. Dirección General de Meteorología. Disponible en: http://servmet.ineter.gob. ni/Meteorologia/climadenicaragua.php Acceso el 6 de diciembre de 2017.

8. Instituto Nicaragüense de Estudios Territoriales. Disponible en: http://www. ineter.gob.ni/ Acceso el 6 de diciembre de 2017.

9. World Health Organization. Human leptospirosis: guidance for diagnosis, surveillance and control. Geneva: WHO; 2003. Disponible en: http:/ / www.who.int/iris/ handle/10665/42667 Acceso el 6 de diciembre de 2017.

10. Chakraborty A, Miyahara S, Villanueva SYAM, Saito M, Gloriani NG, Yoshida S. A novel combination of selective agents for isolation of Leptospira species. Microbiol Immunol. 2011;55(7):494-501. 
11. Levett PN, Morey RE, Galloway RL, Turner DE, Steigerwalt AG, Mayer LW. Detection of pathogenic leptospires by real-time quantitative PCR. J Med Microbiol. 2005;54(Pt 1):45-9.

12. Merien F, Portnoi D, Bourhy P, Charavay F, Berlioz-Arthaud A, Baranton G. A rapid and quantitative method for the detection of Leptospira species in human leptospirosis. FEMS Microbiol Lett. 2005; 249(1):139-47.

13. Organización Panamericana de la Salud. Impacto del huracán Mitch en Centro América. Bol Epidemiol. 1988;19(4). Disponible en: http://cidbimena.desastres.hn/docum/ops/publicaciones / Epidemiologico/BE_v19n4.pdf Acceso el 6 de diciembre de 2017.

14. Saito M, Villanueva SYAM, Chakraborty A, Miyahara S, Segawa T, Asoh T, et al. Comparative Analysis of Leptospira Strains Isolated from Environmental Soil and Water in the Philippines and Japan. Appl Environ Microbiol. 2013;79(2):601-9.

15. Benacer D, Woh PY, Mohd Zain SN, Amran F, Thong KL. Pathogenic and saprophytic Leptospira species in water and soils from selected urban sites in peninsular Malaysia. Microbes Environ. 2013; 28(1):135-40.

16. Ashford DA, Kaiser RM, Spiegel RA, Perkins BA, Weyant RS, Bragg SL, et al. Asymptomatic infection and risk factors for leptospirosis in Nicaragua. Am J Trop Med Hyg. 2000;63(5-6):249-54
17. Chakraborty A, Miyahara S, Villanueva SYAM, Saito M, Gloriani NG, Yoshida S-I. A novel combination of selective agents for isolation of Leptospira species. Microbiol Immunol. 2011;55(7):494-501.

18. Jorge S, Schuch RA, de Oliveira NR, da Cunha CEP, Gomes CK, Oliveira TL, et al. Human and animal leptospirosis in Southern Brazil: A five-year retrospective study. Travel Med Infect Dis. 2017; 18:46-52.

19. Mwachui MA, Crump L, Hartskeerl R, Zinsstag J, Hattendorf J. Environmental and Behavioural Determinants of Leptospirosis Transmission: A Systematic Review. PLoS Negl Trop Dis. 2015; 9(9):e0003843.

20. Lau CL, Smythe LD, Craig SB, Weinstein P. Climate change, flooding, urbanisation and leptospirosis: fuelling the fire? Trans $\mathrm{R}$ Soc Trop Med Hyg. 2010;104(10):631-8.

21. Flores BJ, Pérez-Sánchez $T$, Fuertes $H$ Sheleby-Elías J, Múzquiz JL, Jirón W, et al. A cross-sectional epidemiological study of domestic animals related to human leptospirosis cases in Nicaragua. Acta Trop. 2017;170:79-84.

22. Rawlins J, Portanova A, Zuckerman I, Loftis A, Ceccato P, Willingham AL, et al. Molecular detection of leptospiral DNA in environmental water on St. Kitts. Int J Environ Res Public Health. 2014;11(8):7953-60.

23. Vijayachari P, Sugunan AP, Shriram AN. Leptospirosis: an emerging global public health problem. J Biosci. 2008;33(4):557-69.
24. Levett PN. Usefulness of Serologic Analysis as a Predictor of the Infecting Serovar in Patients with Severe Leptospirosis. Clin Infect Dis. 2003;36(4): 447-52.

25. Climate Prediction Center, National Weather Service. El Niño/Southern Oscillation (ENSO) Diagnostic Discussion. Disponible en: http://www.cpc.ncep. noaa.gov/products / analysis_monitoring/enso_disc_may2016/ Acceso el 6 de diciembre de 2017.

26. Somarriba BF, Sheleby-Elías J, Fischer RSB, Jirón W, Duttmann C. Leptospirosis in Central America: Techniques for Diagnosis and Molecular Characterization. Curr Trop Med Rep. 2017;4(2):70-6.

27. Fischer RSB, Somarriba BF. Challenges to Diagnosing Leptospirosis in Endemic Regions Require Urgent Attention. Curr Trop Med Rep. 2017;4(2):57-61.

28. Stoddard RA, Gee JE, Wilkins PP, McCaustland K, Hoffmaster AR. Detection of pathogenic Leptospira spp. through TaqMan polymerase chain reaction targeting the LipL32 gene. Diagn Microbiol Infect Dis. 2009;64(3):247-55.

Manuscrito recibido el 3 de mayo de 2017. Aceptado para publicación, tras revisión, el 5 de octubre de 2017. 
ABSTRACT

\section{Detection of Leptospire spp. in animals and in environmental samples from peridomestic areas in Nicaragua}

Keywords Leptospirosis; epidemiological factors; zoonoses; Nicaragua.
Objective. The objective of this study was to determine the epidemiological characteristics of leptospirosis in pets and in humans in peridomestic settings in Nicaragua between 2014 and 2016.

Methods. The samples were taken in areas where cases were confirmed in humans using non-probabilistic sampling in 10 of the country's 17 departments. This included 112 urine samples from pets, 129 water samples, and 69 soil samples in order to isolate leptospires in Ellinghausen-McCullough-Johnson-Harris (EMJH) medium. Furthermore, the microscopic agglutination test (MAT) was applied to 263 samples of animal serum, and 88 isolates were analyzed using PCR.

Results. In $32.6 \%(101 / 310)$ of the samples, spirochetes were isolated: $23.2 \%(26 / 112)$ in the pet urine, $47.3 \%(61 / 129)$ in water samples, and $20.3 \%(14 / 69)$ in soil samples. Isolation analysis showed significant differences $(p<0.05)$ between departments for the different types of samples, and isolation was more frequent in water than in soil $(\mathrm{OR}=3.49$; $\mathrm{CI} 95 \%$ : 1.56-7.80). In total, $14.1 \%(37 / 263)$ of the animals were reactors in the microscopic agglutination test. The most frequent serogroup was Icterohaemorrhagiae $(40 \%)$. PCR analysis to identify pathogenic species of leptospires resulted in $10.2 \%$ $(9 / 88)$ positive isolations.

Conclusions. This research demonstrates that pets and environment conditions play an important role in the emergence of outbreaks of leptospirosis, and confirms the endemic behavior of the disease in Nicaragua.
RESUMO

\section{Detecção de Leptospira spp. em animais e em amostras ambientais de áreas peridomiciliares na Nicarágua}

Palavras-chave
Objetivo. Descrever as características epidemiológicas da leptospirose em animais domésticos e em casos de leptospirose humana em áreas peridomiciliares na Nicarágua entre 2014 e 2016.

Métodos. As amostras foram coletadas por amostragem não probabilística em áreas com casos confirmados de leptospirose humana em 10 das 17 províncias do país. Foram analisadas 112 amostras de urina de animais domésticos, 129 amostras de água e 69 amostras de solo com o uso do meio de cultura padrão para o isolamento de leptospiras (Ellinghausen-McCullough-Johnson-Harris, EMJH). Além disso, foi realizado o teste de aglutinação microscópica em 263 amostras séricas de animais e 88 isolados foram analisados com a técnica de PCR.

Resultados. Em 32,6\% (101/310) das amostras foram isoladas espiroquetas, sendo $23,2 \%(26 / 112)$ isoladas na urina de animais domésticos, 47,3\% (61/129) nas amostras de água e $20,3 \%(14 / 69)$ nas amostras de solo. Houve diferença significativa $(\mathrm{P}<0,05)$ entre as províncias no isolamento nos diferentes tipos de amostras analisadas, sendo o isolamento mais frequente nas amostras de água que de solo $(\mathrm{OR}=3,49$; IC95\%: 1 , $56-7,80)$. Reatividade no teste de aglutinação microscópica foi observada em $14,1 \%$ $(37 / 263)$ das amostras de animais. O sorogrupo mais frequentemente isolado foi Icterohaemorrhagiae (40\%). A técnica de PCR demonstrou que 10,2\% (9/88) dos isolados eram positivos para espécies patogênicas de leptospiras.

Conclusões. Esta pesquisa demonstra que os animais domésticos e o entorno têm papel importante no surgimento de surtos de leptospirose e confirma o comportamento endêmico da doença na Nicarágua.

Leptospirose; fatores epidemiológicos; Zoonoses; Nicarágua 